DOE/EMSP/60017-6

FINAL REPORT

U.S. Department of Energy

\title{
REMOVAL OF TECHNETIUM, CARBON TETRACHLORIDE, AND METALS FROM DOE PROPERTIES
}

Thomas E. Mallouk, Sherman M. Ponder

Department of Chemistry, The Pennsylvania State University, University Park, PA 16802

John G. Darab

Pacific Northwest National Laboratory, P.O. Box 999, Richland, WA 99352

Project Number 60017

Grant Number DE-FG07-97ER14822

September 1997-September 2000 


\section{TABLE OF CONTENTS}

Page

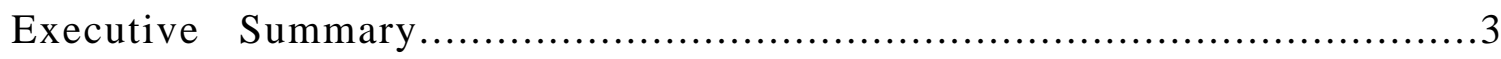

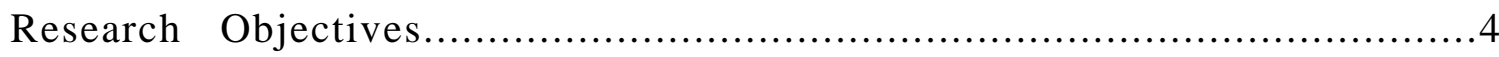

1. Remediation of aqueous waste streams using supported zero-valent iron ....4

2. Liquid-liquid separation methods for recovery of cesium.......................4

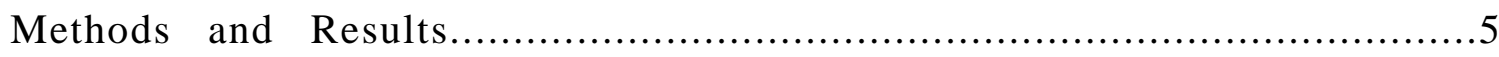

1. Reduction and Immobilization of $\mathrm{ReO}_{4}{ }^{-}$and $\mathrm{TcO}_{4}{ }^{-}$by Ferragels...................5

2. Characterization of Supported Zero Valent Iron Nanoparticles......................9

3. Remediation of Aqueous Metal Ions...............................................10

4. Remediation of Chlorinated Organics.............................................12

5. Recovery of Cesium from Aqueous Solutions as Inorganic Salts.................13

Relevance, Impact, and Technology Transfer...............................................16

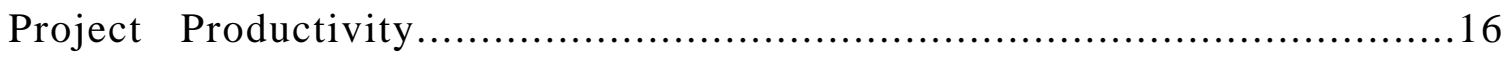

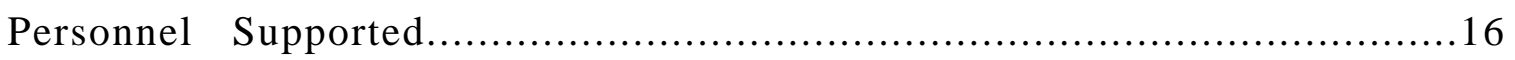

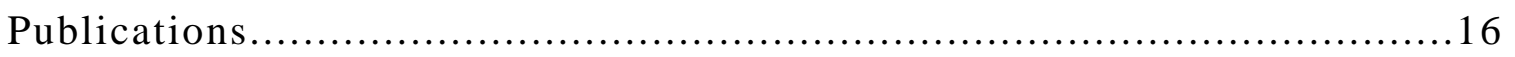

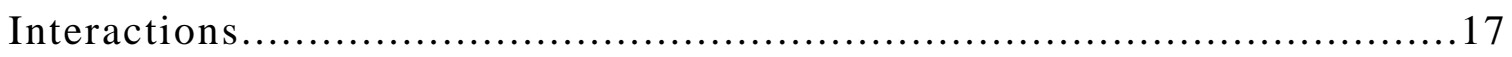

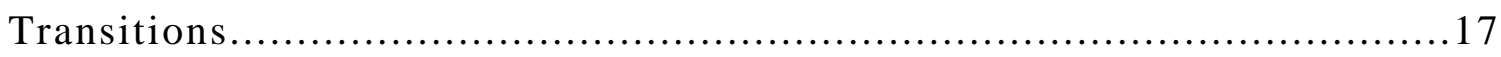

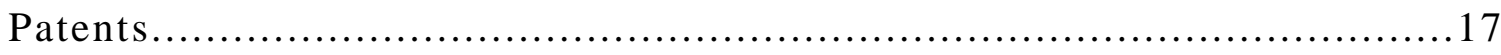

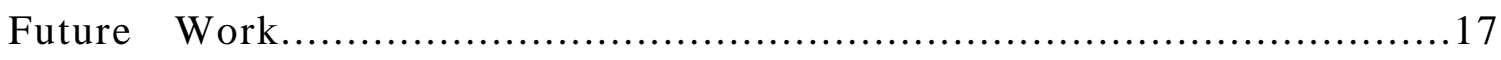

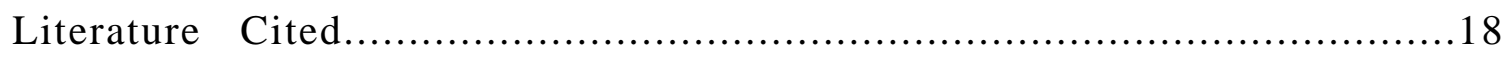

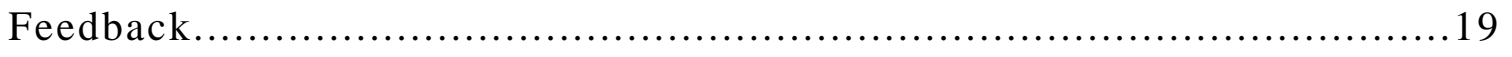




\section{Executive Summary}

This report describes a three-year project on the development of supported zero-valent iron materials ("Ferragels") for removal of reducible metal ions and chlorinated organics from aqueous streams. While zero valent iron remediation is becoming an increasingly mature technology, very little work has been done on the synthesis of materials that are targeted for particular applications. In the three years that this work was supported by DOE-EMSP, the Penn State and PNNL groups have shown that Ferragels generally have higher activity and greater flexibility for environmental remediation applications than other forms of zero valent iron. Because the iron is highly dispersed, the remediation is faster and more efficient. The support material can also serve to pre-concentrate reactants, mediate electron transfer reactions, and nucleate the growth of product phases. These factors can exert an even greater effect than the degree of dispersion on the rates of remediation and background corrosion. Optimized Ferragels are now the most efficient forms of zero valent iron for remediation of $\mathrm{TcO}_{4}^{-}, \mathrm{Cr}(\mathrm{VI}), \mathrm{Pb}(\mathrm{II})$, and tetrachloroethylene (TCE).

Technetium (Tc) removal is a high priority need for the Hanford tank system. The proposed waste separation, pretreatment, and vitrification processes for this waste involve separation into solid high level waste (HLW) and liquid low level waste (LLW) fractions. The latter will contain most of the Tc, in the +7 oxidation state as the pertechnetate ion $\left(\mathrm{TcO}_{4}^{-}\right)$as well as in lower oxidation states. Vitrification of these wastes is very problematic because $\mathrm{Tc}^{7+}$ compounds are volatile at high temperatures, and the presence of large quantities of nitrate and nitrate in the LLW ensures that the melts remain oxidizing. The current methods of choice for separation of Tc compounds from the other ions in the LLW stream involve ion-exchange or liquid-liquid separation processes. Ferragels were shown to reduce and immobilize the Tc effluents from these processes on vitrifiable supports. Tests conducted at Penn State, using $\mathrm{ReO}_{4}{ }^{-}$as a surrogate for $\mathrm{TcO}_{4}^{-}$, and at PNNL using Tc-containing simulant solutions, demonstrated the viability of this approach. This aspect of the work involved the synthesis of new support materials, detailed kinetic, physical characterization, and corrosion studies, and fabrication/characterization of glass and glass-ceramic waste forms. Similar synthetic and analytical strategies were applied to remediation of aqueous wastes containing halogenated organics, especially trichloroethylene (TCE) and soluble metal ions, such as mercury, lead, and chromium, which have been identified as medium-priority needs of the Environmental Management Science Program. New carbon-based Ferragels that are tailored for rapid remediation and slow corrosion have been synthesized and tested. Long-term column tests and corrosion studies were initiated under conditions that simulate real use conditions.

A second major thrust of this work was to develop liquid extraction and continuous flow operations for separation of ${ }^{137} \mathrm{Cs}$ from aqueous streams. These new methods, developed at Penn State, are a modification of the tetraphenylborate (TPB) precipitation process used at the DOE Savannah River Site (SRS). The modified process greatly minimizes the contact time between $\mathrm{Cs}$ and TPB, which has recently caused serious problems associated with the generation of volatile organics (primarily benzene) in large-volume reactors. In this work, the extraction process was optimized and demonstrated on a pilot scale at 1/10 the throughput needed at SRS. 


\section{Research Objectives}

The basic objective of our DOE-supported research were to develop simple chemical and materials approaches to the remediation of aqueous wastes. DOE properties and custodial properties contain groundwater and process streams with a variety of contaminants, including radionuclides, such as ${ }^{137} \mathrm{Cs}$ and ${ }^{99} \mathrm{Tc}$, as well as toxic metal ions, which include $\mathrm{Cr}(\mathrm{VI}), \mathrm{Pb}(\mathrm{II})$, and $\mathrm{Hg}(\mathrm{II})$, and chlorinated organics, such as $\mathrm{CCl}_{4}$. A primary focus of our work has been to test and modify supported zero-valent iron nanoparticles ("Ferragel") and to apply the reductive capacity of the iron-bearing material to render these contaminants innocuous; by reductive dechlorination in the case of the organics, by separation and immobilization in the case of aqueous metal ions, and by separation and vitrification in the case of radionuclides.

1. Remediation of aqueous waste streams using supported zerovalent iron. In our originally proposed research, the remediation of technetium and other reducible contaminants focused on the rational application of surface chemistry to enhance reactivity, the study of reaction kinetics, and the characterization of reaction products. Various supports and combinations of zero valent metals were studied and optimized for particular remediation applications. In general this work has been quite successful. We have shown that Ferragels are very effective in removing $\mathrm{TcO}_{4}{ }^{-}$from alkaline low activity waste (LAW) simulants, even in the presence of excess nitrite, which is also a reducible anion. Iron-on-silica Ferragel also removes $\mathrm{TcO}_{4}{ }^{-}$from $\mathrm{pH}$ neutral solutions that simulate the eluents from tecnhetium ion exchange resins. Other Ferragels (iron-on-resin and nickel/iron on carbon) are very efficient and rapid remediants for aqueous $\mathrm{Cr}(\mathrm{VI}), \mathrm{Pb}(\mathrm{II})$, and tetrachloroethylene (TCE) solutions. In the batch tests, these optimized forms of supported iron were clearly superior to the traditional in situ barrier material (iron filings) in terms of both the speed of the reaction and the total amount of contaminant removed. These promising results led us to add investigation into arsenic and cadmium remediation to our original schedule of lead, chromium, and mercury.

Our research on the synthesis and reaction kinetics of Ferragels evolved in tandem with work by other groups on unsupported zero valent iron. What was initially thought to be a simple reaction governed by pseudo-first order heterogeneous kinetics now appears to follow complex, mixed zero and first order kinetics. The fact that we are seeing these kinetics in the reduction of aqueous metal ions by nanoparticles, while others are reporting the same for organic contaminants with iron filings, suggests that these complex kinetics are intrinsic to all elemental iron reactions with aqueous oxidants and have general applicability.

In the course of these targeted studies we observed that the support materials, while inert to the contaminants, affect the surface area, dispersion, and corrosion kinetics of iron nanoparticles, often in unexpected ways. For example, we found that unsupported nanoiron is anodically limited in the reduction of trichloroethylene (TCE), and is actually a slower remediant than low surface area iron filings. We therefore added a fuller physical and mechanistic characterization of iron in various forms to our original work plan. We studied the corrosion of supported and unsupported iron particles using a technique that was recently developed to test the electrochemical reactivity of catalyst powders, ${ }^{1}$ and this work has helped us understand the reactivity of different forms of iron.

2. Liquid-liquid separation methods for recovery of cesium. In addition to our work on remediation of technetium, reducible metal ions, and chlorinated organic molecules, recent events at the Savannah River site (SRS) led us to initiate an additional study on the separation and disposal of aqueous ${ }^{137} \mathrm{Cs}$. Cesium is now separated 
from liquid waste streams as the tetraphenylborate (TPB) salt, although other separation methods, including inorganic and organic ion exchange, have been intensively researched over the past decade. The radiolytic generation of benzene, a volatile, toxic, and flammable organic liquid, is a serious drawback in the TPB process. Although remediation of cesiumcontaing wastes was not part of our original proposal, we were able to devise a simple liquid-liquid process for separating TPB from cesium, and recovering the latter as an inorganic salt. In addition to providing an easily vitrfified form of cesium, this process minimizes the contact time of ${ }^{137} \mathrm{Cs}$ and TPB. It should therefore substantially eliminate the internal radiolysis reaction that produces benzene. The continuous liquid-liquid process for cesium recovery that was developed in the final stages of this project could be important to DOE in that its application should allow resumption of suspended remedation activities at SRS. This process should be easily scalable to operations at SRS. While our process does not involve the use of Ferragels, it does fit the general theme of simple chemical and materials solutions to aqueous remediation problems of interest to DOE.

\section{Methods and Results}

\section{Reduction and Immobilization of $\mathrm{ReO}_{4-}$ and $\mathrm{TcO}_{4}{ }^{-}$by Ferragels}

Preliminary work with Ferragel involved testing at Penn State using the perrhenate anion $\left(\mathrm{ReO}_{4}^{-}\right)$as a non-radioactive surrogate for $\mathrm{TcO}_{4}{ }^{-}$. Several studies have shown that perrhenate is very similar to pertechnetate chemically. In particular, work at PNNL has established that the chemistry of the two ions under processing conditions involved in vitrification is essentially identical. ${ }^{2}$ The two ions also have very similar aqueous chemistry, although $\mathrm{TcO}_{4}{ }^{-}$is more easily reduced than $\mathrm{ReO}_{4}{ }^{-}$. Reactions (1) - (3) indicate the formal equilibrium potentials of the relevant half-cell reactions, under conditions $(\mathrm{pH}$ 13.5) of the double-shell slurry feed (DSSF) simulant. ${ }^{3}$

$$
\begin{array}{ll}
\mathrm{ReO}_{4}^{-}(\mathrm{aq})+4 \mathrm{H}^{+}(\mathrm{aq})+3 \mathrm{e}^{-}=\mathrm{ReO}_{2}(\mathrm{~s})+2 \mathrm{H}_{2} \mathrm{O}(\mathrm{l}) & \mathrm{E}_{\mathrm{o}}^{\prime}=-0.548 \mathrm{~V} \\
\mathrm{TcO}_{4}^{-}(\mathrm{aq})+4 \mathrm{H}^{+}(\mathrm{aq})+3 \mathrm{e}^{-}=\mathrm{TcO}_{2}(\mathrm{~s})+2 \mathrm{H}_{2} \mathrm{O}(\mathrm{l}) & \mathrm{E}_{\mathrm{o}}^{\prime}=-0.361 \mathrm{~V} \\
\mathrm{Fe}(\mathrm{OH})_{2}(\mathrm{~s})+2 \mathrm{H}^{+}(\mathrm{aq})+2 \mathrm{e}^{-}=\mathrm{Fe}(\mathrm{s})+2 \mathrm{H}_{2} \mathrm{O}(\mathrm{l}) & \mathrm{E}_{\mathrm{o}}{ }^{\prime}=-0.855 \mathrm{~V}
\end{array}
$$

In tests carried out in solutions containing $\mathrm{NaOH}, \mathrm{Na}_{2} \mathrm{CO}_{3}$, and $\mathrm{NaNO}_{3}$ at appropriate concentrations for the DSSF simulant as well as $0.017 \mathrm{M} \mathrm{KReO}_{4}$, iron-onzirconia Ferragel removed $\approx 97 \%$ of the $\mathrm{ReO}_{4}$ - from the solution after 24 hours. The solids from this reaction were collected by filtration through a $0.2 \mu \mathrm{m}$ filter, and scanning electron microscopy (SEM) and energy-dispersive x-ray analysis (EDAX) were used to analyze them. From SEM it was clear that a solid material other than the original iron particles had sorbed onto the support. The EDAX analysis indicated a high rhenium content in these solids, as well as iron, presumably present as residual zero-valent iron and/or as the insoluble reaction product.

From Pourbaix diagrams and related data ${ }^{4,5}$, it is likely that the sorbed rhenium compound is $\mathrm{ReO}_{2}$. The latter is insoluble in aqueous solution, and intermediate oxidation states, $\operatorname{Re}(\mathrm{V})$ and $\operatorname{Re}(\mathrm{VI})$, are unstable with respect to disproportionation. $\mathrm{Fe}^{0}$ should not be capable of reducing $\mathrm{ReO}_{2}$ to the zero-valent state, and previous studies have established that $\mathrm{Fe}(\mathrm{II})$ compounds are relatively unreactive with $\mathrm{TcO}_{4}{ }^{-6}$ Further, the quantitative 
reaction of $\mathrm{ReO}_{4}^{-}$with Ferragel argues against simple adsorption without reduction as the mechanism for removal from solution.

At PNNL, detailed evaluations were conducted using Ferragel supported on zirconia $\left(\mathrm{ZrO}_{2}\right)$ powders (which can tolerate high $\mathrm{pH}$ conditions) for the removal of $\mathrm{TcO}_{4}{ }^{-}$ from several simplified LAW simulants. The original plan was to use a graded approach to simulant selection, starting with a solution containing containing $\mathrm{NaOH}, \mathrm{Na}_{2} \mathrm{CO}_{3}$, and $\mathrm{NaNO}_{3}$, then adding $\mathrm{NaNO}_{2}$ to the simulant, then other components that influence corrosion behavior such as $\mathrm{SO}_{2}^{-}, \mathrm{F}^{-}$, and $\mathrm{Cl}^{-}$, then finally a full DSSF simulant. We had also made arrangements to test Ferragels in actual DSSF waste.

Multiple 24-hour batch contact tests were performed on the zirconia-supported Ferragel using a simulant containing $7.4 \mathrm{M} \mathrm{Na}^{+}, 3.8 \mathrm{M} \mathrm{OH}^{-}, 3.1 \mathrm{M} \mathrm{NO}_{3}{ }^{-}$, and $0.27 \mathrm{M}$ $\mathrm{CO}_{3}{ }^{2-}$ at a $\mathrm{pH}$ of $\approx 14$ ( simulant $\mathrm{S} 1$ ) as well as a slightly more complex industrial LAW simulant with a $\mathrm{pH}$ of 11 (simulant S2). Pertechnetate concentration varied, with the highest being about $12 \mathrm{mM}$. The results of these batch contact experiments are summarized in Figure 1.

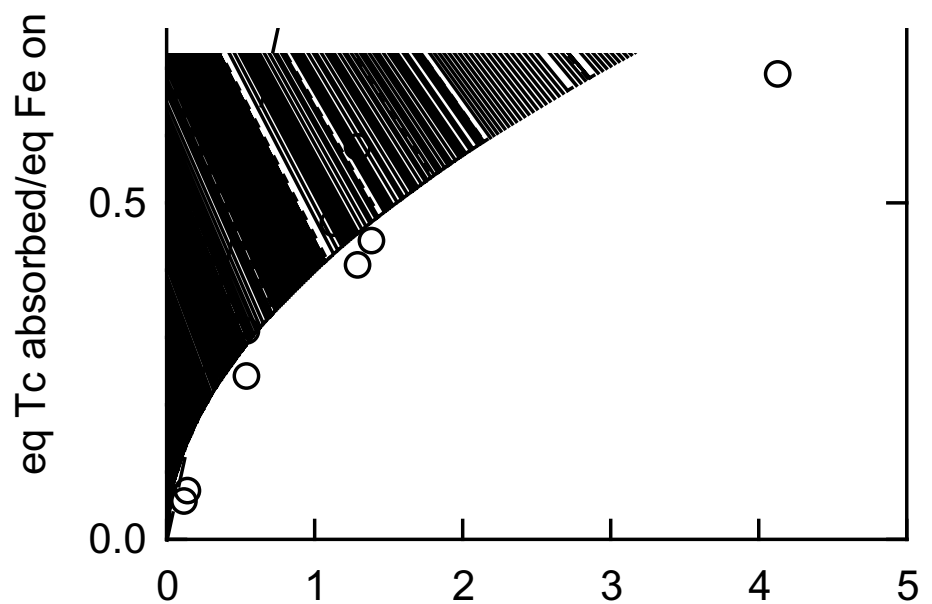

eq Tc in starting solutiont/eq Fe on suppor
Figure 1. Plot of the amount of technetium removed (represented as equivalents of Tc absorbed on the Ferragel per equivalent of iron on the Ferragel) vs. the relative amount of technetium in the simulant (represented as equivalents of Tc in the starting solution per equivalent of iron on the Ferragel). All of the data were obtained from simulant S1 except for the two data points near the origin, which were obtained from simulant S2.

The long-dashed lines in Figure 1 represent a stoichiometric reaction between the presumed $\mathrm{Fe}^{0}$ and the $\mathrm{TcO}_{4}{ }^{-}$, while the short-dashed curve and solid line represents fits of the amount of technetium absorbed to a Tafel dependence on the concentration of pertechnetate in the starting solution.

Fe K-edge X-ray absorption near edge structure (XANES) spectroscopy performed on as-prepared Ferragel materials indicates that the iron occurs predominantly $(\approx 85 \%)$ as $\mathrm{Fe}(0)$ with the balance best fit to Fe(III). A good fit to the XANES data was obtained using a mixture of iron foil and hematite $\left(\mathrm{Fe}_{2} \mathrm{O}_{3}\right)$. However, the presence of a small concentration of $\mathrm{Fe}(\mathrm{II})$, which should occur if the expected low temperature oxidation layer of magnetite $\left(\mathrm{Fe}_{3} \mathrm{O}_{4}\right)$ also was present between the iron and the hematite, could not be ruled 
out. The XANES analysis also does not distinguish easily between different forms of $\mathrm{Fe}_{2} \mathrm{O}_{3}$, such as hematite and maghemite.

Metallic iron exhibits active-passive corrosion behavior. The solid curve in Figure 1 represents a best fit to the data considering typical active (as opposed to passive) corrosion kinetics. The corrosion potential (which is different from the equilibrium reduction potentials given in eqs. 1-3) is reached when the rates of iron oxidation and solute reduction are equal. For the case at hand, the corrosion potential depends on the concentration of reducible solute (pertechnetate) in the starting solution, and the rate of reduction follows a Tafel dependence, confirming that an active corrosion process is occurring.

The data represented in Figure 1 demonstrate that zirconia supported Ferragels can efficiently remove pertechnetate from high $\mathrm{pH}$, high ionic strength solutions. As much as $17 \mathrm{wt} \% \mathrm{TcO}_{2}$ has been loaded onto Ferragel using this approach. Equal success in removing pertechnetate from simulants containing high concentrations of $\mathrm{NaOH}, \mathrm{NaNO}_{3}$, and $\mathrm{NaNO}_{2}$ was also achieved. This last result is quite important, because nitrite is also reducible and a therefore a potential interferent, since it is present in tank waste in much higher concentration than pertechnetate. The zirconia support material alone as well as ferrihydrite $(\mathrm{FeOOH})$ and magnetite were also tested in control experiments, and they showed no ability to remove pertechnate from these solutions.

Although these results are quite encouraging, Hanford Site contractors decided during the course of this work that a select, proprietary organic ion-exchange resin (BNFL Super-Lig) would be the technology of choice for removing pertechnetate from LAW. Thus, additional work in testing Ferragels in more complex simulants and actual LAW was put on hold. The Hanford contractors did, however, express an interest in using Ferragels to treat the large volumes of technetium-containing eluent that would be generated in removing technetium from the ion-exchange resins. The suggested simulant for this eluent consisted almost entirely of water. Thus, for a first approximation water (deionized, passed through activated carbon to remove organics, and distilled) containing $\approx 0.05 \mathrm{mM}$ $\mathrm{TcO}_{4}^{-}$was used as a simulant to test technetium removal by Ferragel.

Our initial experiments on removal of pertechnetate from ion-exchanger eluent involved XANES and EXAFS (extended X-ray absorption fine structure) spectroscopic studies at the Stanford Synchrotron Radiation Laboratory (SSRL) with collaborators at the Lawrence Berkeley National Laboratory (LBNL). Unsupported nanophase iron, nanophase iron supported on silica gel (i.e., Ferragel), and silica gel by itself (as a control) were contacted with the water/pertechnetate simulant for approximately 24 hours. Following up on our previous LAW simulant tests, XANES and XAFS analysis were also performed on unsupported nanophase iron after being contacted for 24 hours with a simulated waste containing $\mathrm{NaOH}, \mathrm{NaNO}_{3}$, and $\mathrm{NaNO}_{2}$ at a $\mathrm{pH}$ of approximately 13. UV-Vis spectroscopy was also used to obtain an estimate of the degree of pertechnetate removal, which showed that in all cases, except for the silica gel alone, almost all $(\approx 99 \%)$ of the $\mathrm{TcO}_{4}{ }^{-}$was removed from the simulant solutions after 24 hours of contacting, consistent with the behavior suggested by Figure 1. As expected, the silica gel alone removed essentially no pertechnetate. XANES results confirmed that the technetium on the Ferragel as well as on the unsupported nanophase iron (in both simulants) occurred in a reduced form, most likely Tc(IV). EXAFS results on these same systems were similar, revealing that the technetium had 6 oxygen neighbors at $2.02 \mathrm{~A}$ and approximately 3 iron neighbors at $3.2 \AA$. This is consistent with the formation of an insoluble amorphous or mixed phase Tc(IV)-Fe(III) oxide. 
Taken together, these results show definitively that Ferragels can efficiently remove pertechnetate from high $\mathrm{pH}$, high ionic strength solutions as well as from neutral $\mathrm{pH}$ solutions. The XANES results indicate another important aspect of the Ferragel technology: the pertechnetate is in a reduced state, most likely Tc(IV) after removal from solution. This reduced form of technetium should provide for a more efficient means of incorporating it into a waste form during vitrification, as the lower oxidation states of technetium allow for lower volatilities.

Unfortunately, despite its potential for separating and immobilizing technetium from column eluents, Hanford Site contractors decided that the Ferragel technology could not be implemented in their flow sheet because it contains iron, which currently limits the waste loading in glass for approximately $70 \%$ of the waste tanks at Hanford. This decision, however, ignores the possibility of incorporating $\mathrm{TcO}_{2}$-loaded Ferragel into its own waste form. In fact, this was our goal from the beginning. We originally proposed that the $\mathrm{TcO}_{2}$-loaded materials could be stabilized separately from the treated waste, either as part of a melter feed for traditional alkali borosilicate waste glass compositions, which are typically melted at temperatures exceeding $1150^{\circ} \mathrm{C}$, or as part of unique glass compositions developed by PNNL which melt at much lower temperatures and provide reducing conditions during melting. Since then, PNNL has been involved with glass development projects for other waste streams.

In particular, PNNL has developed a glass frit (called the NBS frit), which is based on an alkali boro-aluminosilicate composition, to encapsulate Rocky Flats plutonium ash and residue. The objective was not to solubilize the waste species in a glass melt but rather to let the glass particles sinter around the ash particles at much lower temperatures, thus encapsulating the plutonium. The NBS glass frit was specially formulated to have a short working range, i.e., it remains relatively rigid to a particular temperature then exhibits a rapid decrease in viscosity. This allows volatile off gas products $\left(\mathrm{CO}_{2}, \mathrm{NO}_{\mathrm{x}}\right.$, water, etc) to escape at low temperatures $\left(<500^{\circ} \mathrm{C}\right)$ thus minimizing batch expansion problems. The waste is then quickly encapsulated beginning at about $600^{\circ} \mathrm{C}$, minimizing the processing time. Here too we need to be concerned about volatile off gas products, which will be liberated from the LAW components, and we are also concerned about encapsulating the waste quickly as at higher temperatures the technetium volatility may become appreciable. Thus, this encapsulation technique and the glass frit developed for it are well suited to the application of stabililzing the $\mathrm{TcO}_{2}$-loaded zirconia or silica supported Ferragels. To this end we successfully encapsulated a $20 \mathrm{wt} \% \mathrm{ReO}_{2}$ loaded zirconia-stabilized Ferragel into the NBS frit at $700^{\circ} \mathrm{C}$ in 4 hours. The resulting glass button, which we have yet to characterize, is shown in Figure 2.

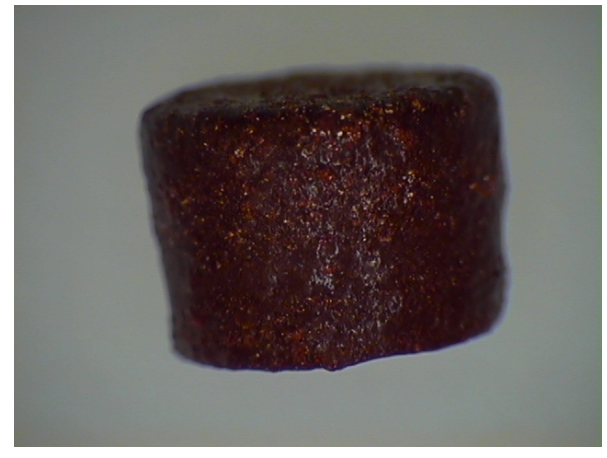

Figure 2. Photograph of a glass button made by encapsulating $20 \mathrm{wt} \% \mathrm{ReO}_{2}$-loaded zirconiasupported Ferragel into an alkali boroaluminosilicate glass frit at $700^{\circ} \mathrm{C}$ for 4 hours. 


\section{Characterization of Supported Zero Valent Iron Nanoparticles}

In our studies on remediation of $\mathrm{TcO}_{4}{ }^{-}$, reducible metal ions, and chlorinated organics, we generate iron nanoparticles through the borohydride reduction of aqueous $\mathrm{FeSO}_{4}{ }^{7}$ In the presence of a support, this process yields iron nanoparticles $(10-30 \mathrm{~nm}$ diameter) that adhere to the surface of the support material. The iron particle size was determined by examination of SEM or TEM micrographs, and by using the Scherrer equation for the XRD peak at $44.64^{\circ} 2 \theta$.

Nitrogen BET analysis showed that unsupported nano-iron produced by this method had a surface area of $21.7 \mathrm{~m}^{2} / \mathrm{g}$. Nano-iron mounted on a resin support had a surface area of $24.4 \mathrm{~m}^{2} / \mathrm{g}$, and the resin itself (PolyFlo, non-porous, hydrophobic particles 20-30 $\mu \mathrm{m}$ in diameter, available from Puresyn, Inc., Malvern PA) had a surface area of 3$3.5 \mathrm{~m}^{2} / \mathrm{g}$. Higher surface area materials, such as porous silica gel, can also be used as supports. 200-400 mesh silica gel had a surface area of $440 \mathrm{~m}^{2} / \mathrm{g}$, while the iron-on-silica Ferragel made from this material had a surface area of $239 \mathrm{~m}^{2} / \mathrm{g}$, indicating occlusion of pores by the lower surface area iron. From micrographs of the finished material, it can be seen that the non-porous resin effectively dispersed the iron nanoparticles over its surface, whereas the porous silica caused dendritic crystallite growth. Despite its higher surface area, iron-on-silica Ferragel reduced $\mathrm{Pb}$ (II) and $\mathrm{Cr}(\mathrm{VI})$ solutions more slowly than resinsupported Ferragels. (Both materials showed faster and more efficient reduction than iron filings). This leads to the conclusion that the surface chemistry of the support and the iron is a more important parameter than the total surface area in remediation reactions.

A detailed analysis of unsupported, silica-supported, and resin-supported nanoscale iron was conducted using AAS, XANES, XPS, and TGA. The general picture that emerged from these studies was that the iron surface in all three materials was similar, with a Fe(III) oxide or hydroxide coating covering particles that are predominantly zero-valent iron. However, electrochemical studies using a powder-impressed electrode in $0.1 \mathrm{M}$ $\mathrm{KClO}_{4}$ showed interesting differences that correlated with activity in remediation reactions. ${ }^{8}$ In these experiments, corrosion potentials and Tafel slopes were measured in order to determine the effect of the surface oxide on the active corrosion process. Passive corrosion rates (i.e., the current density $i_{\text {corr }}$ at the corrosion potential $E_{\text {corr }}$ ) also gave an estimate of the utility of each form of iron in long- and short-term applications. Results of these studies are shown in Figure 3. Interestingly, the resin-supported nano-iron corrodes similarly to iron filings. $\mathrm{E}_{\text {corr }}$ was $-735 \mathrm{mV}$ (vs. SHE) for iron-on-resin Ferragel, and $\mathrm{i}_{\text {corr }}$ was $3.98 \times 10^{-4} \mathrm{~A} / \mathrm{m}^{2}$, corresponding to a corrosion rate of $4.8 \times 10^{-4} \mathrm{~mm} / \mathrm{yr}$. Iron filings (40 mesh, Fisher) had an $\mathrm{E}_{\text {corr }}$ of $-710 \mathrm{mV}$, an $\mathrm{i}_{\text {corr }}$ of $6.61 \times 10^{-4} \mathrm{~A} / \mathrm{m}^{2}$, and a corrosion rate of $7.9 \times 10^{-4} \mathrm{~mm} / \mathrm{yr}$. In this medium, both materials showed anodic control of the corrosion process, due to the fact that the slopes of the anodic Tafel plots were less than the slopes of the cathodic plots, but no definite regions of passivation were present on either voltammetric plot. $9,10,11$

In striking contrast, unsupported nano-iron had an $\mathrm{E}_{\text {corr }}$ of $-65 \mathrm{mV}$, an $\mathrm{i}_{\text {corr }}$ of 5.0 $\mathrm{x} 10^{-5} \mathrm{~A} / \mathrm{m}^{2}$, and a corrosion rate of $6.0 \times 10^{-5} \mathrm{~mm} / \mathrm{yr}$. Additionally, there were two passivation regions; the first between -40 and $-20 \mathrm{mV}$ and the second beginning between -10 and $0 \mathrm{mV}$. These passivation regions are consistent with initial formation of green rust, followed by the transformation to goethite $(\alpha-\mathrm{FeOOH})$. This behavior is surprising because the only difference in the synthesis of the resin-supported and unsupported nanoiron is the addition of the support. The particle size and morphology of the iron are very similar for the two materials. 


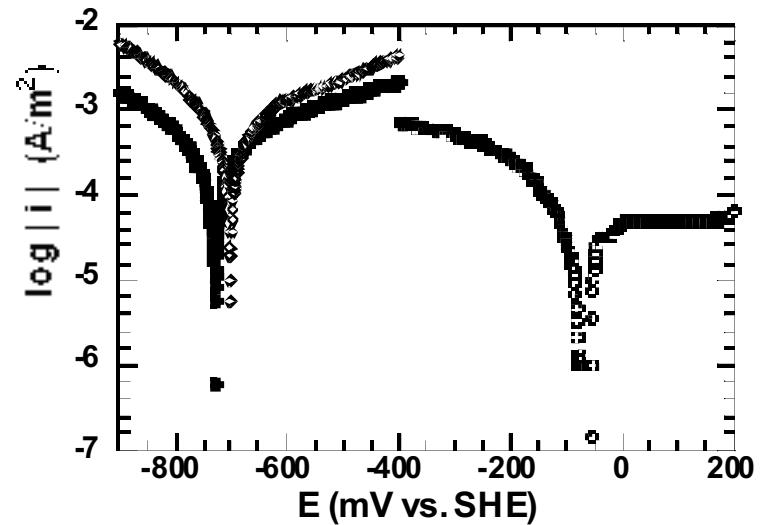

Figure 3. Corrosion plots of iron-bearing materials. $\grave{o}=$ iron-on-resin Ferragel, $\varnothing=$ =iron filngs, $\AA=$ =unsupported nano-iron.
A plausible explanation for this behavior is that the iron oxide formed in the reaction makes a passive barrier on the nano-iron surface, but not on the iron filings or on iron-on-resin Ferragel. On resin-supported Ferragel, the iron is dispersed across the support, and with iron filings (which contain only about $80 \%$ iron as obtained, with the remainder primarily in the form of carbon) the surface contains about 50 atomic \% carbonaceous materials as determined by XPS. In contrast, the unsupported nano-iron presents a clean, hydrophilic surface which apparently becomes rapidly covered with a passive oxide. While anodic control of corrosion was observed by Farrell, et al. in experiments with magnetite-coated iron

wires, ${ }^{9}$ they did not observe the same degree of passivity or the very positive values of $\mathrm{E}_{\text {corr }}$ that we find for freshly prepared unsupported nano-iron, or the very negative $\mathrm{E}_{\text {corr }}$ values we observe for iron-on-resin Ferragel. The moral of the story is that the support exerts a strong influence not only on the sorption and pre-concentration of the contaminant (see results below for metal ions and TCE), but also on the activity of the nanophase iron itself.

\section{Remediation of Aqueous Metal Ions}

We previously reported that rates of reduction for $\mathrm{Cr}(\mathrm{VI})$ and $\mathrm{Pb}$ (II) appeared consistent with pseudo first order kinetics. ${ }^{12}$ However, more detailed experiments showed that this simple model was insufficient to describe the full kinetics. ${ }^{13}$ For $0.100 \mathrm{~g}$ of ironon-resin Ferragel exposed to $100 \mathrm{~mL}$ of $0.500 \mathrm{M}$ contaminant, we found initial rates of $1.18 \mathrm{hr}^{-1}$ for $\mathrm{Cr}$ (VI) and $1.44 \mathrm{hr}^{-1}$ for $\mathrm{Pb}$ (II). We have also added the reduction of $\mathrm{Hg}$ (II) to our research and show an initial rate of $4.90 \mathrm{hr}^{-1}$ under the same conditions. By comparison, iron filings $(0.100 \mathrm{~g})$ gave much slower initial rates $\left(0.22 \mathrm{hr}^{-1}\right.$ for $\mathrm{Cr}(\mathrm{VI})$ and $0.44 \mathrm{hr}^{-1}$ for $\mathrm{Pb}(\mathrm{II})$ ) despite the fact that their $\mathrm{i}_{\text {corr }}$ value was similar at $\mathrm{E}_{\text {corr }}$ in $0.1 \mathrm{M}$ $\mathrm{KClO}_{4}$ solution. Effectively, the corrosion potential is shifted positive by the oxidizing metal ions and in this case the form of iron with the lower surface area and smaller anodic Tafel slope (iron filings) is the poorer remediant.

The rates of reduction increase not only as the contaminant concentration is held constant and the amount of iron added is increased, but also increase when the initial concentration of contaminant is decreased while the amount of iron is held constant. The former is expected for a hetergeneous reaction with pseudo first order kinetics, but the latter reveals a rate dependence on the contaminant concentration that is inconsistent with such a simple model. A similar rate dependence on initial contaminant concentrations has been noted by other researchers for zero valent iron remediation of organics, ${ }^{14,15,16}$ and currently, mixed zero and first order models encompassing possible dual site sorption are being proposed. ${ }^{17,18}$ 
The fact that rate dependence on concentration occurs not only with iron filings but also with the nanoparticles on Ferragels, and the fact that this concentration dependence occurs for both organic and inorganic contaminants, strongly suggests that the behavoir is intrinsic to all zero-valent iron aqueous reductions. Demonstrating a consistent kinetic model that accounts for concentration dependence is thus important for applications of reactive barriers in general.

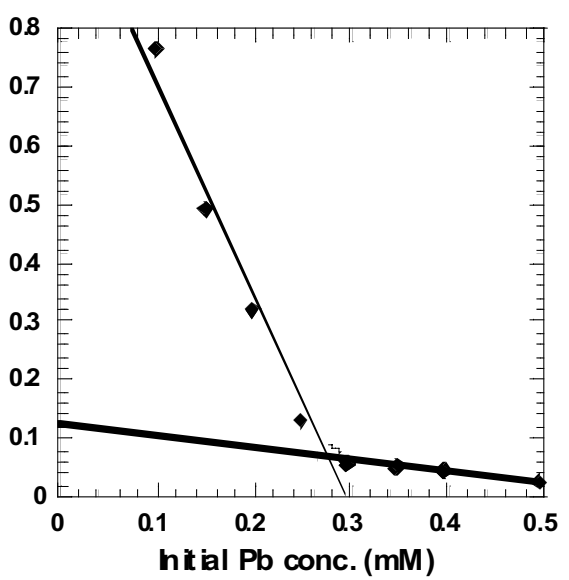

Figure 4. Apparent rate constant $\left(\mathrm{min}^{-1}\right)$ vs. intial $\mathrm{Pb}$ concentration. The amount of iron-on-resin Ferragel was $0.100 \mathrm{~g}(0.405$ mmol $\mathrm{Fe}$ ) in $100 \mathrm{~mL}$ solution, and the breakpoint occurs at $0.28 \mathrm{mM} \mathrm{Pb}$.
Plots of the apparent first-order rate constants show a large increase when the number of moles of iron equals 8-10 times the number of moles of contaminant. (See Figure 3.) This increase is 10 times greater for $\mathrm{Pb}(\mathrm{II})$, and about 5 times greater for $\mathrm{Cr}(\mathrm{VI})$. This suggests that about $10 \%$ of the total nanophase iron is located at active sites. We are obliged to express this figure in terms of total iron, instead of total surface iron, because the fraction of surface atoms is currently unknown. ${ }^{19}$ It should also be noted that complex kinetics would seem to preclude the linear behavior shown in Figure 4, but it is likely that the tested concentrations all happened to fall within a pseudo first order regime of an overall mixed order reaction.

Over 60 days, 1.414 moles of iron $(0.456$ $\mathrm{g}$ iron-on-resin Ferragel, $0.239 \mathrm{~g}$ nano-iron, $0.100 \mathrm{~g}$ filings) were exposed to $1.000 \mathrm{~L}$ of 1.500 $\mathrm{mM} \mathrm{Cr}(\mathrm{VI})$ and $\mathrm{Pb}(\mathrm{II})$ solutions. Ferragel removed $40 \%$ of the $\mathrm{Cr}$ and $>99 \%$ of the lead. Nano-iron reduced $45 \%$ of the $\mathrm{Cr}$ and $65 \%$ of $\mathrm{Pb}$. Iron filings reduced $10 \% \mathrm{Cr}$ and $15 \%$ of the $\mathrm{Pb}$. For $0.50 \mathrm{mM}$ solutions, the rate of reduction was even faster for Ferragels, with the Ferragels removing 5 times the $\mathrm{Cr}$ as an equal weight of filings, and 21 times more $\mathrm{Cr}$ than filings on the basis of moles of iron present. This increase points up the greater number of active surface sites present on the Ferragel. As the concentration of contaminant is lowered, the number of sites that are saturated, and thereby anodically limited, decreases, and the rate of reduction increases.

Of particular interest was the fact that in all cases $90 \%$ of the reaction was complete within the first 48 hours of exposure. This suggests that, along with the lower initial corrosion rate, that iron-on-resin Ferragel may be a suitable material for column eluent applications and permeable barriers. Because Ferragel reacts more quickly and more completely with the contaminant, especially during the critical first 48 hours of exposure, smaller volumes of Ferragels may be used in place of iron filings, allowing for a reduction in the total amount needed for eluent treatment and a lower excavation volume for a reactive barrier.

Reaction products of lead(II) remediation show by XRD that $\mathrm{Pb}$ (II) is reduced to $\mathrm{Pb}(0)$. Also tentatively idenified were $\mathrm{Pb}(\mathrm{OH})_{2}$ and $\mathrm{PbO} \bullet \mathrm{xH}_{2} \mathrm{O}$. The XRD pattern is complex and contains other peaks yet to be identified, but which most likely contain oxidized iron or lead/iron oxides. XPS showed all $\mathrm{Pb}$ to a depth of $25 \AA$ to be in the $2+$ oxidation state, with all of the surface iron oxidized to the $2+$ or $3+$ state. At low $\mathrm{Cr}(\mathrm{VI})$ loading $(0.50 \mathrm{mM})$ the main reaction product was clearly goethite, with too little $\mathrm{Cr}$ in the bulk to show up in XRD. At high $\mathrm{Cr}$ loading $(50 \mathrm{mM})$ the reaction products were too 
poorly crystalline to indentify by powder XRD. XPS of Cr products showed both the Fe and the $\mathrm{Cr}$ present in the 3+ oxidation state. These results are consistent with the subsequent exolution and deposition of initial products to form a chromite, which has previously been discussed in the literature for $\mathrm{Cr}(\mathrm{VI})$ reduction by iron filings. $\mathrm{Hg}$ reduction produces a highly crystalline insoluble product that has not yet been identified on XRD. Surface $\mathrm{Hg}$ was also found to be in the $2+$ oxidation state by XPS.

\section{Remediation of Chlorinated Organics}

We have also investigated the use of zero-valent iron (supported and unsupported) and nanophase nickel-iron bimetallic compositions for the reductive dehalogenation of chlorinated organics. Because it has been widely studied in the literature, and because of its relevance both to DOE and other environmental concerns, tetrachloroethylene (TCE) was chosen for initial studies. These tests were carried out using EPA method 502.2, with a sample loading for each vial of $5 \mathrm{~g}$ per $40 \mathrm{ml}$ of TCE solution, and an initial TCE concentration of $5.4 \times 10^{-4} \mathrm{M}$. Interestingly, we found that iron filings pre-treated with borohydride reduced TCE much faster than unsupported nano-iron, despite its much lower surface area $\left(1.5 \mathrm{~m}^{2} / \mathrm{g}\right.$ compared to $\left.20 \mathrm{~m}^{2} / \mathrm{g}\right)$. This result is in line with the corrosion potential measurements described above, and follows from the fact that the product of TCE reduction does not alter the passive oxide that forms on the nano-iron surface. In contrast, in the case of $\mathrm{Cr}$ (VI) reduction, unsupported nano-iron is a good remediant. However, in this case the product is a mixed $\mathrm{Cr}$-Fe oxide phase that is apparently non-passivating.

In the process of testing various high-surface area supports, such as silica gel, we determined from kinetic data that Vulcan XC-72 carbon made hydrophilic with 4aminosulfonic acid is an excellent support because it is electronically conducting (allowing for a bipolar reaction mechanism) and has high adsorbtivity for organic compounds, and is already used in the removal of chlorinated compounds from waste streams. To investigate the bipolar kinetic pathway, we also studied a 4:1 nickel:iron composition, both supported and unsupported.

When the Ni-Fe catalyst was used unsupported, as well as supported on hydrophilic carbon, we achieved removal of TCE down to the minimum concentration levels (MCL) specified by the EPA $(0.005 \mathrm{mg} / \mathrm{L})$ within $120 \mathrm{~min}$. Currently we can achieve the 2-hour dehalogenation of TCE using only $0.1 \mathrm{~g}$ of solid per vial that contains $40 \mathrm{ml}$ of $1.8 \times 10^{-4} \mathrm{M}(23.4 \mathrm{ppm})$ TCE solution. By way of comparison, other research groups have reported reactions that required $150 \mathrm{hrs}$ using $13 \mathrm{~g}$ of iron filings per $40 \mathrm{ml}$ of solution in which the initial TCE concentration was 100 ppm..$^{20}$

The rate of dehalogenation using $0.1 \mathrm{~g}$ Ni-Fe supported on hydrophilic carbon was $1.58 \mathrm{hr}^{-1}$. When silica was used as a support, a reduction rate of only $0.34 \mathrm{hr}^{-1}$ was observed (Figure 5). By comparison, unsupported nanophase iron had a dehalogenation rate of only $0.0042 \mathrm{hr}^{-1}$, and when supported on hydrophilic carbon it was $0.17 \mathrm{hr}^{-1}$. These results are interesting and are in line with both the corrosion studies done on nanophase iron (Figure 3), and with the proposed bipolar mechanism for $\mathrm{Ni}-\mathrm{Fe}$ on a conductive support. XPS and ICP data demonstrated that the unsupported Ni-Fe nanoparticles have about $62 \%$ of all the nickel located on the surface of the particles (within the $\sim 5 \mathrm{~nm}$ probe depth of XPS), whereas $75 \%$ of the iron is below the probe depth of XPS. Control experiments with nanophase nickel and with a commercial mixture of sintered Ni:Fe powder (50:50 weight ratio, 100 mesh) showed minimal reactivity with TCE, again consistent with a bipolar reaction mechanism in which TCE is reduced at the Ni surface as Fe is oxidized. 


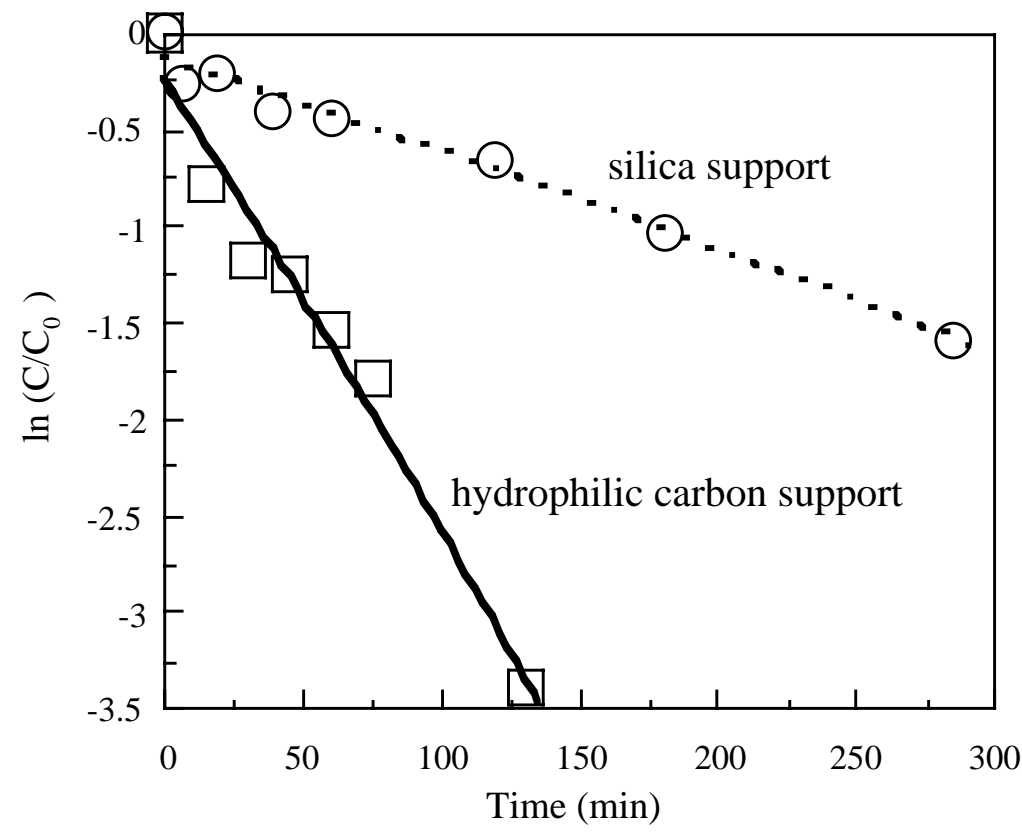

Figure 5. First-order rate plot for dehalogenation of TCE by nanophase 4:1 nickel:iron on silicagel and hydrophobic carbon supports.

In the course of the dehalogenation reaction, chloride ions are produced. Assuming that for each degraded TCE molecule three chloride ions are produced, chloride release to the solution phase was not quantitative. Although no lower chlorinated reduction products were detected by GC, this observation still needs to be investigated by GC/MS and by analysis of the residual solids. Nevertheless, the concentration of chloride ions was in the $10^{-4} \mathrm{M}$ range, and increased with increasing TCE disappearance.

\section{Recovery of Cesium from Aqueous Solutions as Inorganic Salts}

While new technologies for removal of ${ }^{137}$ Cs from high level waste (HLW), in particular silicotitanate and other inorganic ion exchangers, ${ }^{21,22,23}$ are now being developed, the older tetraphenylborate (TPB) process is still the method of choice at the DOE Savannah River site. Sodium tetraphenylborate has long been known to precipitate heavy alkali metal ions such as $\mathrm{Cs}^{+}$or $\mathrm{Rb}^{+}$, quantitatively from aqueous solutions. The reaction is relatively free of interferences, and the efficacy of TPB as a precipitating anion is attested to by the fact that it is used as a reagent for gravimetric analysis of heavier alkali metals. ${ }^{24,25,26,27}$

A problem with recovery of ${ }^{137} \mathrm{Cs}$ using TPB is that the radiation emitted by this isotope can both decompose the TPB and raise the process stream temperature. The result of these effects is to create bubbles of volatile organics that periodically burst at the surface, creating a serious safety hazard. Recent events at the DOE's Savannah River Site exemplify this problem: ${ }^{137} \mathrm{Cs}$ was to be recovered by precipitation with TPB in a batch process performed in million gallon tanks. During the period of time required to mix and then collect the precipitate in such large vessels, an unacceptable amount of hydrophobic organics (primarily benzene) was generated. ${ }^{28}$ This safety hazard caused the shutdown of the entire waste processing line. A second drawback is that final disposal of TPB salts presents a problem, because of the internal radiolysis reactions (which again generate benzene) and the large fraction of organic matter that must be decomposed in processing to make stable wasteforms. 
We have developed liquid-liquid extraction processes that recover Cs from CsTPB as inorganic (chloride or carbonate) salts. Our initial work in this area involved recovery of $\mathrm{Cs}$ as $\mathrm{CsCl}$ and TPB as NaTPB; the latter could be recycled to the aqueous waste stream and used to precipitate more Cs. ${ }^{29}$ The process involves dissolving CsTPB in acetone, and then adding tripropylamine and $\mathrm{HCl}$ to generate water-soluble $\mathrm{CsCl}$ and precipitate solid $\mathrm{NH}\left(\mathrm{C}_{3} \mathrm{H}_{7}\right)_{3}$ TPB according to reaction (4). The $\mathrm{CsCl}$ was quantitatively recovered by extraction with water followed by evaporation. Acetone was then recovered by filtration, and free tripropylamine and aqueous NaTPB were recovered by reaction sequence (5). Overall the process involves stepwise stoichiometric addition of $\mathrm{HCl}$ and $\mathrm{NaOH}$ to generate water, $\mathrm{CsCl}$, and NaTPB from CsTPB. While our initial experiments were done in batch mode, a plausible continuous flow process was also proposed. ${ }^{29}$

$$
\mathrm{Cs}^{+}+\mathrm{TPB}^{-}+\mathrm{NH}\left(\mathrm{C}_{3} \mathrm{H}_{7}\right)_{3}{ }^{+}+\mathrm{Cl}^{-} \rightarrow \mathrm{NH}\left(\mathrm{C}_{3} \mathrm{H}_{7}\right)_{3} \mathrm{TPB}_{(\mathrm{s})}+\mathrm{CsCl}_{(\mathrm{aq})}
$$

$$
\begin{aligned}
& \mathrm{NaOH} \\
& \mathrm{NH}\left(\mathrm{C}_{3} \mathrm{H}_{7}\right)_{3}{ }^{+} \mathrm{TPB}^{-} \rightarrow \mathrm{NH}\left(\mathrm{C}_{3} \mathrm{H}_{7}\right)_{3}{ }^{+}+\mathrm{TPB}^{-} \rightarrow \mathrm{Na}^{+} \mathrm{TPB}^{-}{ }_{(\mathrm{aq})}+\mathrm{H}_{2} \mathrm{O}+\mathrm{N}_{\left(\mathrm{C}_{3} \mathrm{H}_{7}\right)_{3}}
\end{aligned}
$$

The primary virtue of this process is to minimize the contact time of Cs and TPB in the solid phase, and to provide a solid form of Cs that is not susceptible to internal radiolysis for final disposal. However conversations with Dr. Major Thompson at SRS identified two problems with the method that would limit its utility to SRS. First, $\mathrm{HCl}$ and halide salts could cause corrosion problems with metal equipment, and second, the volatility and flammability of acetone could make the process unsafe. These problems were overcome by using propylene carbonate (flash point $132^{\circ} \mathrm{C}$ ) in place of acetone, and by redesigning the process to eliminate chloride and recover $\mathrm{Cs}$ as $\mathrm{CsNO}_{3}$.

As in the first process, Cs is precipitated using NaTPB, and the solid is immediately separated from the aqueous solution by filtration. CsTPB is then dissolved in propylene carbonate $(70 \mathrm{~mL} / \mathrm{g}, 32 \mathrm{mM})$. An equal volume of aqueous $\mathrm{NaNO}_{3}$ solution is added, along with an smaller volume of tripropylamine, and the mixture is agitated. This results in a clear three-phase mixture, in which the lighter and heavier organic phases (tripropylamine and propylene carbonate) flank the aqueous phase. The aqueous phase is then decanted and evaporated to yield a second white solid, which is a mixture of $\mathrm{NaNO}_{3}$ and $\mathrm{CsNO}_{3}$. By NMR, the aqueous portion does not contain significant amounts of TPB. ICP-AES analysis of Cs in the aqueous phase shows that the extraction of Cs is essentially quantitative $(100 \pm 3 \%)$. The tripropylamine appears to dissolve slightly in the propylene carbonate and promote separation from the aqueous phase; in any event, no solid solutes are recovered from the tripropylamine phase, but without it the amount of Cs recovered in a single extraction decreases. Temperature-dependent studies show that this process is driven by the favorable entropy of exchanging sodium ions into the PC phase. The efficacy of this separation process derives from the fact that a 15 -fold molar excess of $\mathrm{Na}^{+}$ ions drives the $\mathrm{Na}^{+} / \mathrm{Cs}^{+}$exchange across the propylene carbonate/water phase boundary.

A significant advantage of this liquid-liquid extraction method is that it is readily adaptable to a continuous flow process, which will dramatically reduce the contact time of aqueous Cs and TPB streams. We are currently testing such a process, based on a crosscurrent filtration that separates solid CsTPB, which is then dissolved in propylene carbonate and processed to form solid cesium nitrate. Cesium nitrate is compatible with vitrification strategies that are now being developed at PNNL. 
This liquid-liquid extraction process has now been sufficiently optimized that we have now moved the process to the continuous flow reactor represented as a block diagram in Figure 6. This reactor, which feeds inlet streams to a plate-and-frame press filter, has been assembled in our laboratory and preliminary tests have been conducted. A concentrated aqueous NaTPB solution is injected as a crosscurrent directly into the process stream. Upon mixing, CsTPB forms immediately as a fine suspension. The suspension is then directed through the plate-and-frame press filter. Currently, our filter has a 7"x7" chamber which is pre-coated with $5 \mathrm{~L}$ of $0.6 \%(\mathrm{w} / \mathrm{w})$ Celite 526 , and the flow rate of the $200 \mathrm{ppm}$ CsTPB suspension is $2 \mathrm{~L} / \mathrm{min}$ at $10 \mathrm{psig}$.

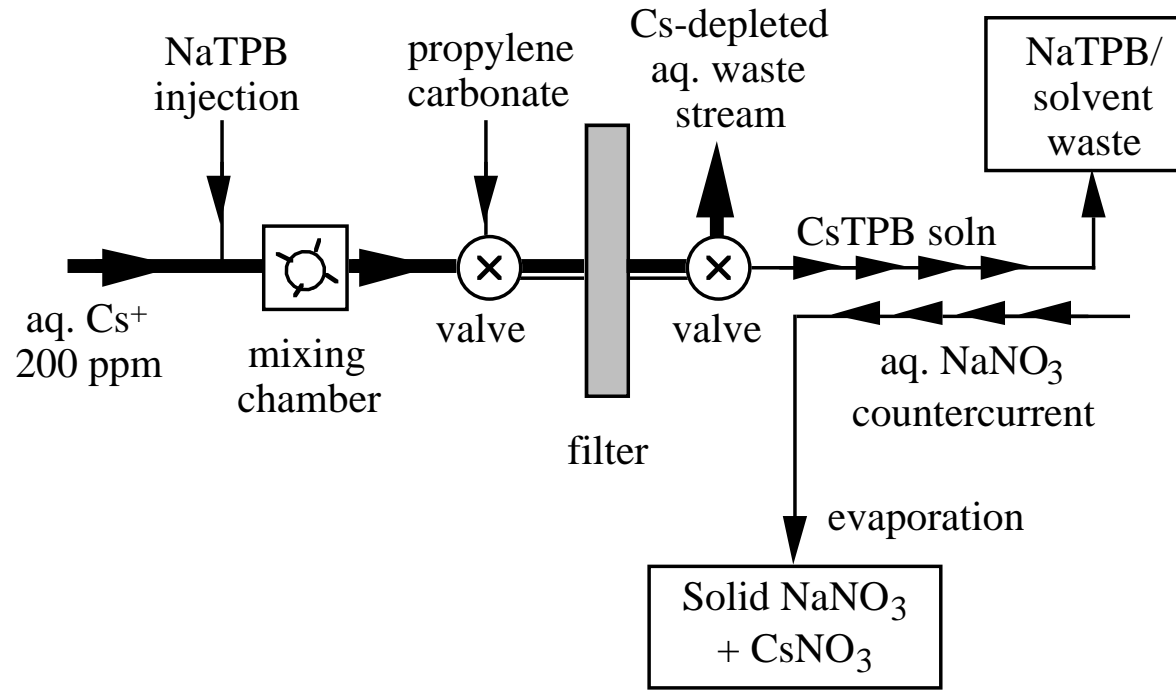

Figure 6. Flow diagram for $\mathrm{Cs}^{+}$ separation using a plate-and-frame filter to collect solid CsTPB. CsTPB is dissolved in propylene carbonate and extracted using a countercurrent flow of aqueous sodium nitrate. Heavy lines indicate flow of the aqueous waste stream. Lighter lines show low volume flows of other reagents.

Currently, we are using this reactor in its simplest form, without valves to direct alternate streams of CsTPB and propylene carbonate to the filter. This means that in order to convert the CsTPB to $\mathrm{CsNO}_{3}$ the flow must be stopped and the filter removed. After blowdown with air at $30 \mathrm{psig}$, the filter papers are scraped to yield filter cakes that contain about $20 \%$ solids. The cakes are first mixed with propylene carbonate, dissolving the CsTPB, and then an aqueous solution containing $\mathrm{NaNO}_{3}$ is added together with tripropylamine to the filtered propylene carbonate solution. Residual propylene carbonate, which is sparingly soluble in water, is washed away from the Celite to permit re-use.

The total exposure time of TPB to the Cs in this process is currently about 15 minutes and is likely to be reduced further by implementation of the valve system that will send alternate flows of the CsTPB suspension, propylene carbonate, and rinse water through the Celite filter bed. In addition to speeding up the process, this strategy will eliminate the filter disassembly/assembly steps and simplify handling of the waste and reagent streams. In order to allow for truly continuous operation, a tandem system with two filters and appropriate control valves will be needed. In this case, the CsTPB suspension can be directed alternately to two filters. One filter can collect CsTPB at the same time as CsTPB is dissolved from the other by injection of propylene carbonate. We note that in this configuration the system could be easily scaled up to operations at SRS, which will require a flow rate of approximately $18 \mathrm{~L} / \mathrm{min}$. The greatly reduced exposure time of TPB to ${ }^{137} \mathrm{Cs}$ should effectively eliminate problems associated with the generation of volatile organics. Any trace organics that do form will be retained in the propylene carbonate phase, from which all radioactive material is removed by aqueous countercurrent extraction. A planned future implementation of this method would use cross-current filtration rather than plate-and-frame to allow for truly continuous operation with no disassembly/reassembly of the filter unit. 


\section{Relevance, Impact, and Technology Transfer}

This project laid the fundamental groundwork for using supported zero valent iron in a variety of practical remediation applications. New materials were synthesized and characterized, and were taken to the proof of concept stage for remediation of technetium, toxic metal ions, and chlorinated organics. Proof of concept experiments were also done with a Cs separation process that may be of interest in DOE Savannah River remediation problems. Currently, our toxic metal and chlorinated organic results are being transferred to the private sector.

Research in other laboratories has been aimed at removing $\mathrm{TcO}_{4}{ }^{-}$from $\mathrm{LLW}$ streams by ion-exchange and liquid-liquid extraction methods. These now appear to be the methods of choice for implementation at the Hanford site. The general strategy is to use hydrophobic cations as anion exchange media, and to elute by reduction of the counter-cation, reduction/complexation of retained Tc species, or ion exchange with other anions, such as $\mathrm{OH}^{-}$or $\mathrm{NO}_{3}^{-}$. Our work on Ferragel reduction of $\mathrm{TcO}_{4}{ }^{-}$and $\mathrm{ReO}_{4}^{-}$dovetails nicely with these procedures. Ferragels provide a means of concentrating and immobilizing (as nonvolatile $\mathrm{TcO}_{2}$ ) Tc from the aqueous eluent streams, free from potentially interfering anions such as $\mathrm{NO}_{3}^{-}$.

\section{Project Productivity}

Almost all of the project goals described in our additional proposal were reasonably accomplished. In addition, some unanticipated useful results (e.g., Cs separation) were obtained.

\section{Personnel Supported}

Lead PI: Thomas E. Mallouk, Dept. of Chemistry, Penn State University, University Park, PA 16802. Tel: 814-863-9637. E-mail: tom@chem.psu.edu.

Co-PI's: Sherman M. Ponder, Dept. of Chemistry, Penn State University, University Park, PA 16802. Tel: 814-863-9791. E-mail: ponder@chem.psu.edu. John Darab, Pacific Northwest National Laboratory, P.O. Box 999, Richland, WA 99352. Tel: 509-375-6608, E-mail: john.darab@pnl.gov.

Graduate students: Sherman M. Ponder, Bettina Schrick, Alexandra Amonette

\section{Publications resulting from DOE-supported work, 1997-present:}

S. M. Ponder and T. E. Mallouk, "Recovery of Ammonium and Cesium Ions from Aqueous Waste Streams by Sodium Tetraphenylborate," Ind. Eng. Chem. Res., $\underline{38}$, 400710 (1999).

S. M. Ponder, J. R. Ford, J. G. Darab, and T. E. Mallouk, "Ferragels: A New Family of Materials for Remediation of Aqueous Metal Ion Solutions," Mater. Res. Soc. Symp. Proc., 556(Scientific Basis for Nuclear Waste Management XXII), 1269-1276 (1999). 
S. M. Ponder, J. G. Darab, and T. E. Mallouk, "Remediation of $\mathrm{Cr}(\mathrm{VI})$ and $\mathrm{Pb}(\mathrm{II})$ Aqueous Solutions Using Supported, Nanoscale Zero Valent Iron," Environ. Sci. Technol., 34, 2564-2569 (2000).

S. M. Ponder, J. G. Darab, J. Bucher, D. Caulder, I. Craig, L. Davis, N. Edelstein, W. Lukens, H. Nitsche, L. Rao, D. K. Shuh, and T. E. Mallouk, "Surface Chemistry and Electrochemistry of Supported Zero Valent Iron Nanoparticles in the Remediation of Aqueous Metal Contaminants," Chem. Mater., 13, 479-486 (2001).

S. M. Ponder, R. Helkowski, and T. E. Mallouk, "Continuous Flow Process for the Separation of Cesium from Complex Waste Mixtures," Ind. Eng. Chem. Res., in press.

Two additional manuscripts, based on the technicium and chlorinated organics results described in the Methods and Results section, are expected to be submitted in the near future.

\section{Interactions}

We were fortunate to have several useful formal and informal interactions with other scientists in the DOE-EMSP program, with TIMs in several of the EMSP focus areas, and with site personnel at DOE Savannah River. Our research results were presented at DOE contractors' meetings, and at national meetings of the Materials Research Society and the American Chemical Society.

\section{Transitions}

We are currently working with a company (PARS Environmental, Princeton, NJ) on the use of Ferragels for in-situ remediation of chlorinated organics and toxic metal ions. They have expressed interest in funding ongoing work in our laboratory in this area.

\section{Patents}

One U.S. patent is pending on the composition of Ferragels and their use in remediation applications.

Future Work is described in detail in our renewal proposal, " Chemical Approaches to the Remediation of Aqueous Wastes Containing Cesium, Technetium, Heavy Metal Ions, and Chlorinated Organics." A portion of this work will likely be supported through industrial collaboration in the future. 


\section{Literature Cited}

1. Long, J. W.; Rolison, D. R. Proc. - Electrochem. Soc. 99-5 (New Directions in Electroanalytical Chemistry II), 125-131 (1999).

2. Darab, J. G.; Smith, P. A. Chem. Mater. 1996, 8, 1004.

3. Schmittroth, F. A.; DeLorenzo, T. H.; Wootan, D. W.; Garbrick, D. Y. Inventories for Low Level Waste Tank Waste; Westinghouse Hanford Co. document WHC-SDWM-RPT-164, prepared for the U.S. Department of Energy Office of Environmental Restoration and Waste Management: Richland, WA 1995.

4. Pourbaix, M. Atlas of Electrochemical Equilibria; Pergamom Press: New York 1966; p. 399.

5. Gorski, B.; Koch, H. J. Inorg. Nucl. Chem. 1969, 31, 3565.

6. Cui, D.; Eriksen, T. E. Environ. Sci. Technol. 1996, 30, 2259 and 2263.

7. Wang, C-B; Zhang, W-X; Environ. Sci. Technol. 1997, 31, 2154.

8. Ponder, S. M.; Darab, J. G.; Mallouk, T. E. "Surface Chemistry and Electrochemistry of Supported Zero Valent Iron Nanoparticles in the Remediation of Aqueous Metal Contaminants," submitted to Chem. Mater.

9. Farrell, J., Kason, M., Melitas, N., Li, T, Environ. Sci. Technol., 2000, 34, 514.

10. Bard, A.J., Faulkner, L.R, Electrochemical Methods, 1980, J. Wiley \& Sons, Inc., NY, pp. 86-114.

11. West, J.M., Basic Corrosion and Oxidation, 2 nd ed., 1986, J. Wiley \& Sons, NY, pp. 85-94.

12. Ponder, S. M.; Ford, J. R.; Darab, J. G.; Mallouk, T. E. "Ferragels: a new family of materials for remediation of aqueous metal ion solutions," Mater. Res. Soc. Symp.

Proc., 556(Scientific Basis for Nuclear Waste Management XXII), 1269-1276 (1999).

13. Ponder, S. M.; Darab, J. G.; Mallouk, T. E. "Remediation of Cr(VI) and Pb(II) Aqueous Solutions Using Supported, Nanoscale Zero Valent Iron," Environ. Sci. Technol. 2000, 34, 2564.

14. Matheson, L.J.; Tratnyek, P.G. Environ. Sci. Technol. 1994, $28,2045$.

15. Johnson, T.L.; Scherer, M.M.; Tratnyek, P.G. Environ. Sci. Technol. 1996, 30, 2634.

16. Johnson, T.L.; Fish, W.; Gorby, Y.A.; Tratnyek, P.G.; J. Contam. Hydrol., 1998, $29,379$.

17. Wust, W.F.; Kober, R.; Schlicker, O.; Dahmke, A. Environ. Sci. Technol. 1999, $33,4304$.

18. Gotpagar, J.K.; Grulke, E.A.; Bhattacharyya, D. J. Haz. Mat., 1998, 62, 243.

19. Arnold, W.A., Kinetics and Pathways of Chlorinated Ethylene and Chlorinated Ethane Reaction with Zero-valent Metals, Ph. D. Thesis, The Johns Hopkins University, 1999.

20. Burris, D., Campbell, T. Environ. Sci. Technol. 1995, 29, 2850.

21. Zheng, Z.; Philip, C. V.; Anthony, R. G.; Krumhansl, J. L.; Trudell, D. E.; Miller, J. E. Ind. Eng. Chem. Res. 1996, 35, 4246.

22. Behrens, E. A.; Sylvester, P.; Clearfield, A., Environ. Sci. Technol. 1998, 32, 101.

23. Zheng, Z.; Anthony, R. G.; Miller, J. E. Ind. Eng. Chem. Res. 1997, 36, 2427.

24. Wittig, G.,v.; Keicher, G. Ruckert A., Raff, P. Ann. Chem. 1949, 563, 110.

25. Amin, A-A. M. Chem. Analyst 1956, 45, 65.

26. Rudorff, I.W.; Zannier, H. Angew.Chem., 1954, 66, 638.

27. Kolthoff, I.M.; Elving, P.J., Eds.; Treatise on Analytical Chemistry, Interscience Publishers, Inc.: New York 1961, p. 373-378.

28. Johnson, J. Chemical and Engineering News, June 7,1999, p. 8.

29. Ponder, S. M.; Mallouk, T. E. Ind. Eng. Chem. Res. 1999, 38, 4007. 


\section{Feedback}

This program was very well managed and did an excellent job of bringing academic scientists together with DOE personnel to think about relevant environmental problems. One area in which the DOE EMSP program could improve would be to establish long-term, consistent scientific objectives that relate to future rather than present DOE-EM needs. This would ensure maximum engagement of the best academic scientists, who typically require continuity of objectives over a period of time longer than three years in order to bring a basic science idea to practical applications. As a relatively young and interdisciplinary program, I believe that EMSP is currently feeling its way in the establishment of its scientific mission. 